\title{
UPAYA PELESTARIAN BAHASA DAN BUDAYA BALI MELALUI PENGEMBANGAN KAMUS SENI TARI BALI
}

\author{
I Nengah Suandi \\ Universitas Pendidikan Ganesha \\ Email: nengah_suandi@yahoo.co.id \\ I Wayan Mudana \\ Universitas Pendidikan Ganesha
}

\begin{abstract}
Abstrak
Dalam upaya pelestarian bahasa dan budaya Bali, kehadiran kamus seni tari Bali yang inovatif sangat penting dan mendesak untuk dilakukan. Berdasarkan latar dasar pikiran di atas, permasalahan yang diangkat dalam makalah ini adalah (1) Bagaimanakah pengembangan kamus seni tari Bali dalam upaya pelestarian bahasa dan budaya Bali? dan (2) Mengapa pengembangan kamus seni tari Bali dapat dijadikan sebagai salah satu upaya pelestarian bahasa dan budaya Bali? Berdasarkan analisis terhadap sejumlah data pustaka dan data di lapanan, dapat ditarik dua buah simpulan. Pertama pengembangan kamus seni tari Bali dapat dilakukan melalui penerapan model penelitian pengembangan yang diadaptasi dari pengembangan perangkat pembelajaran model 4-D, yang meliputi Define, Design, Develop, dan Disseminate. Kegiatan pada tahap define terdiri atas (1) melakukan analisis kebutuhan dengan mengadakan survai terhadap aneka kamus bahasa Bali, khususnya kamus seni tari; (2) mengumpulkan data mentah berupa kata-kata atau istilah-istilah seni dari berbagai sumber (lisan dan tertulis) dan ditulis ke dalam daftar kata; (3) melakukan klasifikasi data secara alfabetis kemudian menggabungkannya menjadi satu satuan daftar kata. Kegiatan pada tahap design (perancangan) terdiri atas 1) menyusun draf kamus dengan langkah-langkah (1) menyusun lema (kata/istilah) yang tergolong istilah seni tari Bali sesuai urutan abjad berdasarkan data yang sudah dihasilkan dan (2) melakukan rekaman gerak tari; (3) mendeskripsikan makna istilah tari Bali ke dalam bahasa Indonesia da bahasa Inggris;i; 2) Melakukan FGD untuk penyempurnaan draf kamus dengan mengundang (1) perwakilan dinas kebudayan provinsi dan kodya/kabupaten se-Bali, (2) pakar perkamusan dari unsur perguruan tinggi, (3) pakar media, (4) pakar budaya, (5) pakar seni tari dan (6) pakar bahasa (bahasa Bali, bahasa Indonesia; 4) melakukan vaildasi ahli dengan mengundang pakar perkamusan, pakar bahasa Bali, pakar bahasa Indonesia, dan pakar bahasa Inggris; dan 5) menyusun draf Kamus Seni Tari Bali Berbasis Teknologi Android (Bali-Indonesia-Inggris) hasil validasi ahli. Kegiatan pada tahap develop dilakukan dengan langkah-langkah (mengembangkan kamus baik dari segi kuantitas maupun secara kualitas; (2) melakukan FGD untuk mendapatkan masukan terkait dengan pengembangan di atas; (3) melakukan uji efektivitas kamus Kegiatas pada tahap disseminate meliputi distribusi kamus baik yang cetak maupun yang android. Kedua penyusunan kamus seni tari Bali dapat dijadikan sebagai salah satu upaya peletarian bahasa dan budaya Bali karena (1) kamus ini memiliki beberapa
\end{abstract}


kelebihan yaitu menggunakan media gambar; berbasis teknologi android; dan menggunakan tiga bahasa (Bali, Indonesia, dan Inggris). Dengan menggunakan media gambar, makna suatu istilah tari akan menjadi semakin jelas. Dengan dua keunggulan ini, seseorang akan lebih mudah belajar tari Bali. Kedua keunggulan ini juga mampu memotivasi pembelajar tari di Bali, khususnya, untuk membaca kamus seni tari dan belajar tari Bali; dan secara tidak langsung dapat menumbuhkembangkan rasa cinta terhadap bahasa Bali. Rasa cinta terhadap bahasa Bali sebagai salah satu cerminan sikap positif terhadap bahasa Bali merupakan modal utama untuk melestarikan bahasa Bali sekaligus budaya Bali. Hal ini bisa dipahami karena bahasa Bali merupakan salah satu unsur budaya Bali sekaligus pembentuk budaya Bali dan (2) Keberadaan kamus seni tari semacam itu tidak hanya dalam rangka memperluas wawasan terhadap berbagai ungkapan simbolik seni budaya Bali, tetapi juga dalam rangka penguatan benteng budaya, pelestarian budaya, dan strategi budaya Bali. Hal ini terkait dengan keberadaan seni sebagai fenomena budaya yang dapat menginspirasi bagi pengembangan seni budaya dan pembentuk kepribadian masyarakat Bali.

Kata kunci: kamus seni tari, pelestarian bahasa dan budaya

Abstract
In an effort to preserve Balinese language and culture, the presence of an innovative Balinese dance dictionary is very important and urgent to do. Based on the background of the above thought, the issues raised in this paper are (1) How is the development of Balinese dance dictionaries in an effort to preserve Balinese language and culture? and (2) Why is the development of Balinese dance dictionary as an effort to preserve Balinese language and culture? Based on an analysis of a number of library and field data, two conclusions can be drawn. First, the development of Balinese dance dictionaries can be done through the application of development research models that are adapted from the development of 4-D model learning tools, which include Define, Design, Develop, and Disseminate. Activities at the define stage consist of (1) conducting needs analysis by conducting surveys of various Balinese dictionaries, especially dance dictionaries; (2) collecting raw data in the form of words or art terms from various sources (oral and written) and written into a list of words; (3) classifying data alphabetically then combining them into one unit word list. Activities at the design stage consist of 1) compiling a dictionary draft with steps (1) compiling entries (words / terms) that are classified as Balinese dance terms in alphabetical order based on data already generated and (2) recording dance movements; (3) describe the meaning of the term Balinese dance into Indonesian and English; $i$; ) Conducting FGDs to improve the dictionary draft by inviting (1) representatives of provincial and district / city cultural offices in Bali, (2) expert campuses from higher education elements, (3) media experts, (4) cultural experts, (5) dance experts and (6) linguists (Balinese, Indonesian; 4) conduct expert verification by inviting expert scholars, Balinese experts, Indonesian experts, and English experts; and 5) compile a draft of the Android Technology-Based Balinese Dance Dictionary (BaliIndonesia-English) as a result of expert validation. Activities at the develop stage are carried out by steps (developing a dictionary in terms of both quantity and quality, (2) 
conducting FGDs to obtain input related to the above development, (3) conducting a Kegiatas dictionary effectiveness test at the disseminate stage including the distribution of good dictionaries which printed or android.The two compilation of Balinese dance art dictionaries can be used as an effort to escape Balinese language and culture because (1) this dictionary has several advantages, namely using media images, based on android technology, and using three languages (Balinese, Indonesian, and English) By using the image media, the meaning of a dance term will become clearer: With these two advantages, one will find it easier to learn Balinese dance, both of these advantages are also able to motivate dance learners in Bali, in particular, to read dance and dictionary dictionaries. Balinese dance, and indirectly can foster a love for language a Bali. The love of the Balinese language as a reflection of a positive attitude towards the Balinese language is the main capital to preserve the Balinese language as well as Balinese culture. This can be understood because Balinese language is one of the elements of Balinese culture as well as forming Balinese culture and (2) The existence of such a dance dictionary is not only in order to broaden insight into various symbolic expressions of Balinese art and culture, but also in the context of strengthening cultural fortifications, preservation culture, and Balinese culture strategy. This is related to the existence of art as a cultural phenomenon that can inspire the development of art and culture and form the personality of the Balinese people.

Keywords: dance dictionary, preservation of language and culture

\section{Pendahuluan}

Hingga saat ini, Bali merupakan salah satu daya tarik bagi masyarakat dunia. Ketertarikan itu tentu bukan semata-mata karena keindahan alamnya, tetapi karena keluhuran kebudayaannya, terutama kesenian daerahnya. Tamu mancanegara yang datang ke Bali tidak hanya ingin menikmati berbagai keindahan alam Bali dan kesenian daerah Bali, tetapi juga ingin mempelajari aneka cabang kesenian Bali. Salah satu cabang kesenian Bali yang terkenal, digemari, dan banyak dipelajari oleh remaja Bali dan para tamu mancanegara adalah seni tari, yang merupakan bagian penting kehidupan masyarakat Bali dan masih tetap terpelihara sampai sekarang. Hal ini tidak terlepas dari keberadaan masyarakat Bali yang mayoritas beragama Hindu dan agama Hindu mendukung kehidupan kesenian tersebut. Menurut Bandem (1996:9), tidak ada satu pun upacara keagamaaan di Bali yang selesai tanpa diikutsetakannya pertunjukan tari Bali.

Belajar seni tari Bali tidak bisa lepas dari bahasa Bali dan budaya Bali karena istilah-istilah yang digunakan menggunakan media bahasa Bali sebagai salah satu unsur budaya Bali. Dalam belajar tari Bali, pemahaman terhadap istilah-istilah tari Bali sangat penting artinya dalam rangka memperagakan gerakan-gerakan tari secara benar dan mantap. Hasil wawancara dengan salah seorang guru tari pada Sanggar Dwi Mekar Singaraja, Wayan Durpa (17 Januari 2016) menunjukkan bahwa orang yang belajar tari Bali mengalami kesulitan dalam memahami berbagai istilah 
seni tari Bali. Hal ini disebabkan oleh terbatasnya kamus istilah tari Bali yang memudahkan belajar tari Bali.

Langer (1982) mengatakan bahwa bahasa merupakan salah satu bentuk ungkapan simbolik. Dalam konteks kebudayaan, sebagai refleksi kemanusiaan dari manusia, yang mana simbol merupakan bagian dari kebudayaan maka ungkapan simbolik tersebut pada dasarnya merupakan refleksi dari kemanusiaan manusia, khususnya dalam keberadaan manusia sebagai makhluk simbolik. Keberadaan bahasa sebagai sistem simbol dan museum budaya inilah nampaknya yang mendasari berbagai pihak mengembangkan kamus dalam berbagai bidang keilmuan. Kesadaran semacam itu dapat disimak dari berkembangnya berbagai jenis kamus istilah dalam masyarakat. Dalam konteks teori semiotika, bahasa diposisikan sebagai teks (Eco, 2009; Hoed, 2004; 2011; Zoest, 1993; Sobur, 2006; Tinarbuko; 2008; Piliang; 2003; 2012; Rusmana, 2014).

Sebab itu kehadiran Kamus Seni Tari Bali Berbasis Media Gambar dan Teknologi Android (Bali-IndonesiaInggris) sangat penting dan mendesak untuk dilakukan di tengah-tengah maraknya perkembangan sanggar seni tari di Bali. Memang ada satu penelitian berjudul Gerak Tari Bali (Bandem, dkk., 1983), tetapi belum sampai memperoleh luaran berupa kamus seni tari Bali. Kenyataan semacam itu juga nampak dalam kamuskamus seni tari Bali yang ada seperti Kamus Budaya Bali I (Sukayana, 2013), Ensklopedi Mini Karawitan Bali (Sukerta, 1998), Ensiklopedi Tari Bali
(Bandem, 1983); Pendokumentasian Gerak-Gerak Bahasa Bali (2000) oleh Kantor Dokumentasi Budaya Bali. Semua kamus tersebut belum dilengkapi dengan konteks gambar belum disertai deskripsi makna dalam bahasa Inggris, dan belum juga berbasis android dalam penyusunannya.

Pengembangan kamus semacam ini terinspirasi oleh adanya beberapa kamus elektronik berbasis teknologi informasi yang sudah pernah dikembangkan sebelumnya (Liu, 2014; Hwang, 2014; Li, 2014). Di samping itu, pengembangan kamus semacam ini juga terinspirasi oleh adanya kamus elektronik berbasis teknologi mobile seperti Pengembangan Aplikasi Kamus dan Penerjemah Bahasa Indonesia Bahasa Bali Menggunakan Metode Rule Based Berbasis Android (Resmawan, Resika Arthana, \& Sunarya, 2015). Pengembangan kamus yang dilakukan tidak terbatas hanya pada pencarian berbasiskan teks, tetapi juga dengan berbantuan alir data multimedia (Jones, 2015). Pelibatan unsur multimedia dalam kamus selain memperkaya konten kamus itu sendiri juga menawarkan fitur yang secara esensial membantu penggunaannya. Dengan pemanfaatan fitur perangkat bergerak dengan lebih optimal, maka interaktivitas antara pengguna dan perangkat dapat lebih ditonjolkan.

Ada beberapa hal yang membedakan buku kamus atau ensiklopedi seni di atas dengan kamus seni tari Bali yang dikembangkan. Pertama kamus/ensiklopedi yang telah ada dalam bidang seni hanya 
menggunakan dua bahasa (Bali dan Indonesia), sedangkan pengembangan kamus dalam penelitian ini menggunakan tiga bahasa (Bali-Indonesia-Inggris). Pertimbangan digunakannya bahasa Inggris dalam pendeskripsian makna karena banyak orang asing yang tertarik bahkan ikut mempelajari tari Bali dengan berbagai ragamnya. Kedua, kamus/ensiklopedi seni tari yang ada belum ada yang diimplementasikan dalam perangkat android serta kamus bahasa yang ada belum ada yang dilengkapi dengan konten multimedia, sedangkan kamus dalam penelitian ini diimplementasikan dalam perangkat android.

Sadar akan pentinya kamus seni tari berbasis media gambar dan teknologi android dan bahasa merupakan bagian dari budaya sekaligus sebagai salah satu unsur pembentuk budaya, dalam makalah ini diangkat dua masalah pokok, yaitu (1) Bagaimanakah pengembangan kamus seni tari Bali dalam upaya pelestarian bahasa dan budaya Bali? dan (2) Mengapa pengembangan kamus seni tari Bali dapat dijadikan sebagai salah satu upaya pelestarian bahasa dan budaya Bali?

\section{Pembahasan}

\section{Pengembangan Kamus Seni Tari Bali}

Mengawali uraian pengembangan kamus seni tari Bali, perlu dikemukakan secara singkat tentang pengertian dan jenis kamus. Kamus merupakan buku acuan yang memuat kata/istilah dan ungkapan yang disusun menurut abjad yang disertai dengan deskripsi kata (cara pengucapan, cara penulisan, dan cara pembentukannya), deskripsi makna (berupa kata dan gambar), dan deskripsi cara kata bergabung dengan kata yang lain. (Cf.Kamus Besar bahasa Indoesia, 2008; Landau, 2001:5; Svensen, 1993). Ada beberapa jenis kamus. Dari segi besar kecilnya jumlah kosakata, kamus dapat dibedakan atas tesaurus (thesaurus) atau ensiklopedia; kamus besar (seperti Kamus Besar Bahasa Indonesia), dan kamus 'biasa'. Dalam sejarah perkamusan Indonesia, dikenal juga Logat Kecil Bahasa Indonesia karya Poerwadarminta (1949) dan Kamus Saku Bahasa Indonesia (1969) oleh Reksosiswojo, dkk. Jenis yang terakhir ini dapat merupakan kamus terbatas, sesuai dengan sasaran peggunanya. Keterbatasan ini dapat berkaitan dengan wilayah atau dialek geografis, misalnya, Kamus Dialek Jakarta oleh Abdul Chaer (1976), atau dengan dialek sosial, misalnya Kamus Bahasa Prokem oleh Prathama Rahardja dan Henri Chambert-Loir (1988) dan Kamus Bahasa Indonesia untuk Remaja karya Ali Marsaban, dkk. (1974), yang khusus bagi kaum remaja.

Berdasarkan bahasa yang digunakan, kamus juga dapat digolong-golongkan sebagai berikut: (1) kamus ekabahasa (monolingual dictionary), yaitu kamus yang memuat lema dari bahasa $X$ dan dideskripsikan dalam bahasa $X$ juga seperti Kamus Besar Bahasa Indonesia dan Kamus Umum Bahasa Indonesia, (2) kamus dwibahasa (bilingual dictionary), yaitu kamus yang 
lemanya dalam bahasa $X$, tetapi deskripsinya dalam bahasa $Y$ seperti Kamus Bahasa Sumbawa-Indonesia, Kamus Bahasa Bugis-Indonesia, Kamus Bahasa Melayu Bali-Indonesia, (3) kamus anekabahasa (multilingual dictionary), yaitu kamus yang lemanya dalam bahasa $X$ dan deskripsinya atau padanannya dalam bahasa Y dan Z. (Zgusta, 1971).

Ditinjau dari segi pendeskripsian lema, kita bisa melihat adanya dua jenis kamus, yaitu kamus yang deskripsinya hanya menggunakan kata-kata verbal seperti jenis kamus yang sudah disebutkan di atas dan kamus yang deskripsinya disertai dengan gambar seperti kamus bahasa Inggris Oxford Advanced Learner's Dictionary of Current English, yang memuat banyak gambar untuk menambah pemahaman tentang lema yang dideskripsikan secara verbal. Kamus ini biasanya digunakan untuk anak-anak yang biasanya lebih banyak gambarnya, bahkan gambar dengan warnawarni yang mencolok. Di samping itu, terdapat kamus istilah, kamus sinonim seperti Kamus Sinonim Bahasa Indonesia karya Harimurti Kridalaksana (1981), kamus antonim seperti Kamus Antonim oleh T. Heru Kasida Brataatmaja, dkk. (1985), kamus homonim seperti Kamus Homonim (Putrayasa, 2009), kamus polisemi, dan kamus serapan. Kamus istilah merupakan kamus yang mempunyai karakteristik tersendiri, dan tergolong kamus yang 'tidak umum' seperti Kamus Linguistik karya Harimurti Kridalaksana (1993). Kamus serapan yang dimaksudkan dalam penelitian ini adalah kamus yang memuat katakata atau istilah-istilah yang berasal dari luar bahasa tertentu dan secara emperis sudah sering dipakai dalam konteks berbahasa tertentu tersebut dengan mengalami penyesuaian ucapan maupun tulisan sesuai dengan ucapan dan tulisan dalam bahasa tertentu tersebut. Contoh kamus serapan adalah Kamus Katakata Serapan Asing dalam Bahasa Indonesia (Badudu, 2003) dan Kamus Serapan dalam Bahasa Bali (Suandi, 2015).

Walaupun telah banyak aplikasi kamus berbasiskan teknologi android yang dikembangkan (Hugeng, 2015; Hwang, 2014; Ibrahim,2014; Chomchalerm, 2014; Mhamunkar, 2013) belum banyak yang menyertakan unsur multimedia visual ke dalam aplikasi kamus tersebut. Adapun multimedia yang digunakan dalam beberapa aplikasi kamus berbasis android adalah dalam bentuk audio yakni pengejaan kata-kata hasil translasi ataupun sebagai media masukan untuk kata-kata yang akan dicarikan terjemahannya dalam bahasa lainnya (Hugeng, 2015; Ibrahim, 2014; Chomchalerm, 2014; Mhamunkar, 2013). Hwang dkk (2014) mengembangkan sebuah aplikasi kamus yang mampu menggabungkan beragam sumber yang telah tersedia secara daring untuk dapat menyediakan hasil pencarian yang lebih luas dengan memanfaatkan koneksi internet. Jones dkk. (2015) mengembangkan aplikasi kamus yang memanfaatkan teknologi kamera dalam perangkat bergerak untuk mendapatkan hasil pencarian yang terdapat dalam kamus bahasa isyarat Amerika. 
Dalam pengembangan aplikasi kamus seni tari Bali sudah tentu akan dapat memberi nilai lebih apabila mampu memanfaatkan fiturfitur multimedia yang tersedia. Hal ini dikarenakan seni tari Bali sendiri merupakan seni yang menonjolkan gerakan sehingga sebuah visualisasi sangat dibutuhkan dalam memberikan pengertian yang lebih baik bagi penggunanya. Adapun penyertaan multimedia terdapat dalam beragam aplikasi sehubungan bahasa dan budaya adalah berupa media yang digunakan untuk pembelajaran (Chachila, 2015; Alavi, 2016; Suhailah, 2015) ataupun disandingkan dengan teknologi Augmented Reality ataupun Virtual Reality (Franza, 2016; Oppermann, 2015) yang sudah tentu memiliki konsep dan metode yang berbeda dengan pemanfaatan kamus.

Android merupakan sistem operasi telepon seluler yang opensource. Android menggunakan Linux sebagai kernelnya. Android saat ini dikembangkan oleh Open Handset Alliance konsorsium yang terdiri atas 34 perusahaan hardware, software dan telekomunikasi. Beberapa perusahaan besar di dalam konsorsium tersebut di antaranya adalah Google, HTC, Intel, Motorola, Qualqomm, T-Mobile dan Nividia.Banyak vendor yang menggunakan sistem operasi Android pada perangkat smartphonenya. Vendor tersebut di antaranya adalah HTC, Motorola, Samsung, LG, HKC, Huawei, Archos, Webstation Camangi, Dell, Nexus, SciPhone, WayteQ, Sony Ericsson, Acer, Philips, T-Mobile, Nexian, IMO, Asus dan lainnya vendor yang meproduksi smartphone Android. Beberapa alasan kenapa Android sangat berkembang pesat di antaranya adalah (1) Lengkap (complete platform) : Android dikatakan lengkap karena Android menyediakan tools untuk membangun software yang sangat lengkap dibanding dengan platform lain. Para pengembang dapat melakukan pendekatan yang komprehensif ketika mereka mengembangkan suatu aplikasi pada platform Android. (2) Terbuka (open source platform) : Platform Android diciptakan di bawah lisensi open source, yaitu para pengembang bebas untuk mengembangkan aplikasi pada platform ini. Android menggunakan Linux kernel 2.6. (3) Bebas (free platform) : Android adalah platform mobile yang tidak memiliki batasan dalam mengembangkan aplikasinya. Tidak ada lisensi dalam mengembangkan aplikasi Android. Android dapat didisribusikan dan diperdagangkan dalam bentuk apapun.

Pengembangan kamus seni tari Bali dirancang mengikuti alur pemikiran penelitian pengembangan (Research and Development) yang diadaptasi dari pengembangan perangkat pembelajaran model 4-D (Define, Design, Develop, dan Disseminate) oleh Thiagarajan (1974). Dengan mengikuti alur pemikiran penelitian pengembangan tersebut, secara lebih rinci, langkah-langkah yang ditempuh dalam penelitian ini adalah sebagai berikut.

Kegiatan pada tahap define terdiri atas kegiatan melakukan analisis kebutuhan dengan mengadakan survai terhadap aneka 
kamus bahasa Bali,yang meliputi (1) Ensiklopedi Tari Bali (1983) oleh I Made Bandem; (2) Kamus Ideal Bahasa Bali, Bali-Indonesia (2012) oleh I Nyoman Djendra; (3) Pendokumentasian Gerak-Gerak Tari Bali (2000) oleh Kantor Dokumentasi Budaya Bali Provinsi Bali; (4) Bahasa Bali (Tata Bahasa dan Kamus Bahasa Lumrah) (1984) oleh SVD J Kersten; (5) Kamus Bahasa Bali. (1983) oleh I W Simpen; (6) Kamus Budaya Bali I.(2013) oleh I Nengah Sukayana; (7) Ensklopedi Mini Karawitan Bali. (1998) oleh Made Pande Sukerta; (8) Kamus Inggris Bali Indonesia. (2006) oleh I Gusti Made Sutjaja; (9) Kamus Bahasa Bali Modern.(2005) oleh I Nengah Tinggen. Kegiatan dilanjutkan dengan mengumpulkan data mentah berupa kata-kata atau istilah-istilah seni dari berbagai sumber (lisan) dan ditulis ke dalam daftar kata; (2) melakukan klasifikasi data secara alfabetis kemudian menggabungkannya menjadi satu satuan daftar kata.

Tahap design (perancangan) yang terdiri atas 1) menyusun draf kamus dengan langkah-langkah (1) menyusun lema (kata/istilah) yang tergolong istilah seni tari Bali sesuai urutan abjad berdasarkan data yang sudah dihasilkan dan (2) melakukan rekaman gerak tari; mendeskripsikan makna istilah tari Bali ke dalam bahasa Indonesia da bahasa Inggris;i; 2) Melakukan FGD untuk penyempurnaan draf kamus dengan mengundang (1) perwakilan dinas kebudayan provinsi dan kodya/kabupaten se-Bali, (2) pakar perkamusan dari unsur perguruan tinggi, (3) pakar media, (4) pakar budaya, (5) pakar seni tari dan (6) pakar bahasa (bahasa Bali, bahasa Indonesia; 4) melakukan vaildasi ahli dengan mengundang pakar perkamusan, pakar bahasa Bali, pakar bahasa Indonesia, dan pakar bahasa Inggris; dan 5) menyusun draf Kamus Seni Tari Bali Berbasis Teknologi Android (BaliIndonesia-Inggris) hasil validasi ahli.

Hasil validasi ahli untuk kamus edisi perdana menunjukkan bahwa nilai rata-rata akhir yang diperoleh untuk kamus versi cetak sebesar 3.6 (kategori valid). Dengan demikian, sesuai pedoman validasi kamus yang telah ditetapkan, dapat dikatakan bahwa draf Kamus Seni Tari Bali versi cetak edisi perdana dinyatakan valid. Secara kuantitatif, memang draf Kamus Seni Tari Bali sudah dinyatakan valid karena skor rata-rata baik rata-rata keseluruhan maupun rata-rata pada tujuh aspek yang dinilai berada di atas 3 . Temuan secara kuantitatif ini juga didukung oleh temuan secara kualitatif, yang pada intinya mengemukakan hal-hal yang positif terhadap draf kamus. Beberapa orang responden menyampaikan beberapa dukungannya terhadap kamus yang disusun seperti tampak berikut ini.

Secara umum, Kamus Seni Tari Bali sudah baik karena memiliki beberapa kelebihan yaitu menggunakan media gambar, berbasis teknologi android, dan menggunakan tiga bahasa (Bali, Indonesia, dan Inggris). Dengan adanya media gambar, makna suatu istilah tari akan menjadi smakin jelas. Dengan kamus berbasis teknologi android, seseorang akan lebih mudah memahami dan 
memperagakan setiap istilah gerakan tari Bali dan pada akhirnya lebih mudah dalam belajar tari Bali. Dengan menggunakan bahasa Indonesia dan bahasa Inggris, kamus ini akan bisa berlaku secara nasional, tetapi juga secara internasional. Di balik itu, ada juga beberapa masukan dari validator yang perlu ditindaklanjuti oleh tim peneliti dalam rangka penyempurnaan kamus ke depan. Masukan-maukan tersebut dikemukakan antara lain (1) Katakata yang sama dengan makna yang berbeda diberi nomor karena katakata seperti itu merupakan homonim atau homofon atau polisemi; (2) Ada beberapa kata/lema yang dobel atau sama yang perlu dicermati; (3) Deskripsi makna dalam bahasa Indonesia untuk sejumlah lema atau istilah tari ada yang belum lengkap sehinga deskripsi makna dalam bahsa Inggrisnya juga tidak lengkap; (4) Sejumlah padanan makna dalam bahasa Inggris kurang pas; (5) Katakata penjelasan yang belum masuk ke dalam bahasa Indoneia agar dicetak miring. (6) Karena ini kamus istilah, tidak perlu menonjolkan lema, langsung saja ke istilahnya; (7) Ejan huruf Latin bahasa Bali pada beberapa istilah agar disesuaikan; (8) Tampilan cover kurang menarik baik dari segi warna, gambar, maupun bingkai cover.

Untuk kamus versi android, sesuai pedoman validasi kamus yang telah ditetapkan, dapat dikatakan bahwa draf Kamus Seni Tari Bali berbasis teknologi android dinyatakan valid (nilai rata-rata 4.3). Dari enam aspek yang diuji tingkat validasinya, tidak satu pun aspek yang dinyatakan tidak valid karena nilai rata-rata semuanya berada pada angka 4 ke atas.

Kegiatan pada tahap develop dilakukan dengan langkah-langkah (1) mengembangkan kamus baik dari segi kuantitas maupun dari segi kualitas; (2) melakukan FGD untuk mendapatkan masukan terkait dengan pengembangan kamus; (3) melakukan uji efektivitas kamus Kegiatas pada tahap disseminate meliputi distribusi kamus baik yang cetak maupun yang android. Pada makalah ini, kegiatan yang dikemukakan baru sampai pada tahap pengembangan (1) dan (2).

Pada tahap pengembangan ini, kegiatan utama yang dilakukan adalah mengumpulkan data dalam rangka pengembangan kamus baik dari segi pengembangan jumlah lema, ketepatan bentuk lema, posisi penempatan lema secara alfabetis, maupun dari segi kejelasan deskripsi maknanya. Data tentang pengembangan kamus terebut digali dari lima kelompok ahli (masingmasing 5 orang sehingga jumlahnya 25 orang), yaitu ahli seni tari, ahli kamus, ahli bahasa Bali, ahli bahasa Indonesia, dan ahli bahasa Inggris yang dikumpulkan dengan metode FGD (Focus Group Discussion). Khusus data tentang pengembangan gambar dikumpulkan dengan metode observasi dengan teknik pancing, rekam, dan catat.

FGD pengembangan kamus dilakukan selama dua hari yaitu tanggal 5 dan 6 Juli 2019 di Ruang Aula Gedung Pascasarjana Universitas Pendidikan Ganesha. Hadi pada acra pembukaan FGD tersbut Ketua LPPM Undiksha yang diakili oleh Sekretaris LPPM-nya, 
Dr. I Made Sugiarta, M.Si. Dalam sambuatannya, beliau menyambut baik pelaksanan FGD terbut demi meningkatkan kualias penelitian. Pada bagian lain, beliau juga menyampaikan selamat atas diterima dan didanaiya dua proposal penelitian dari Undiksha oleh LPDP Kementerian Keuangan RI. Pada bagian akhir sambutannya, beliau berharap semoga FGD yang dilaksanakan bisa berjalan dengan lancar dan membuahkan hasil yang sesuai dengan harapan.

Peserta FGD berjumlah 50 orang. Mereka terdiri atas lima kelompok ahli yaitu kelompok ahli tari, ahli kamus, ahli bahasa Bali, ahli bahasa Indoneia, dan ahli bahasa Inggris. Di samping itu, peserta juga berasal dari Kepala Dinas Kebudayan Kodya/Kabupaten se-Bali. Daftar nama dan pembagian tugas masingmaing kelompok dikemukakan dalam tabel berikut. Adapun deskripsi tugas mereka adalah sebagai berikut.

Kelompok Dinas Kebudayaan se-Bali, ditugasi mengecek/mencermati bagian kamus dari segi (1) kemenarikan sampul depan; (2) kemenarikan tampilan tulisan pada sampul depan; (3) kemenarikan tampilan tata letak tulisan sampul depan; (4) kemenarikan tampilan judul; (5) kemenarikan huruf yang dipakai; (6) kejelasan dan ketepatan judul; (7) kejelasan isi bagian prakata sehingga mudah dipahami; (8) sistematika sajian prakata; (9) kejelasan isi bagian pendahuluan sehingga mudah dipahami; (10) sistematika sajian bagian pendahuluan dll.
Kelompok ahli dan praktisi tari ditugasi (1) mengecek dan melengkapi istilah tari yang belum tercantum pada kamus; (2) mengoreksi deskripsi makna bahasa indonesia masing-masing istilah tari; (3) mengecek kesesuaian gambar/foto dengan deskripsi makna; (4) mengecek adanya pemunculan istilah tari yang ganda; (5) dll. Kelompok ahli kamus ditugasi (1) mengecek kelengkapan petunjuk kamus; (2) mengecek kejelasan petunjuk kamus; (3) mengecek kemenarikan tampilan kamus; (4) mengecek struktur kamus; (5) mengecek penulisan lema dan sublema secara alfabetis; (6) mengedit kamus berdasarkan tata penulisan kamus; (7) memperbaiki definisi/deskripsi makna berdasarkan teori linguistik.

Kelompok ahli bahasa Bali ditugasi (1) mengecek ketepatan bentuk lema dan sublema/turunan istilah tari; (2) mengecek ketepatan penulisan istilah seni tari sesuai ejaan bahasa bali yang erlaku dll. Kelompok ahli bahasa Indonesia ditugasi (1) mencermati pemakaian bahasa indonesia secara keseluruhan; (2) mengecek ketepatan deskripsi makna bahasa indonesia dari segi kaidah bahasa indonesia baku (logika, gramatika, dan ejaan terbaru); (3) mengecek keserasian deskripsi makna bahasa indonesia dengan gambar dll. Kelompok ahli bahasa Inggris ditugasi (1) mengecek ketepatan deskripsi makna bahasa inggris dari segi logika dan gramatika, dan ejaan ; (2) mengecek keserasian deskripsi makna bahasa indonesia dengan gambar dll. Kelompok ahli IT ditugasi mencermati kamus aplikasi 
dari segi (1) perwajahan kamus (desain per halaman); (2) komposisi ( warna dan teks/huruf); keterbacaan (jenis dan ukuran font, dan kemudahan melihat konten); (4) layout dan penyajianikon, penyajian fitur, proporsi penyajian multimedia); (5) interaktivitas (navigasi, kemudahan perolehan perolehan informasi, hubungan antarlaman terkait); (6) mengedit tata letak gambar, dll

Di antara peserta, ada yang ditunjuk sebagai narasumber engan tugas (1)nmenyiapkan pokok-pokok pikiran secara tertulis bahan diskusi (halhal yang perlu dicermati sesuai dengan bidang kelompoknya masing-masing); (2) menyampaikan hasil diskusi kelompok pada sidang pleno, dll. Selanjutnya, tim periset ditugasi (1) menyampaikan pengantar pada awal diskusi kelompok-kelompok; (2) mencatat proses dan hasil diskusi, dll

Hasil FGD yang dilakukan selama dua hari adalah sebagai berikut.(1) Dalam kamus, hendaknya digunakan makna konseptual bukan makna refensial (rujukan). Di samping itu, juga digunakan makna logis. (2) Penyampaian definisi, tidak menggunakan sinonimi, antonimi, atau bentuk lain dari istilah yang didefinisikani. (3) Definisi sebaiknya dimulai dari fitur semantik yang paling umum diikuti fitur semantik khusus. Jka istilahnya tergolong nomina maka kata inti definisinya juga nomina. Tulisan judul kamus terlalu besar.(4) Tambahkan Bahasa Bali, Bahasa Indonesia, dan Bahasa Inggris pada judul kamus. (5) Foto pada sampul terlalu besar sehingga perlu diperkecil. (6) Simbol korek api yang dipegang filosofinya kurang mengena. Bisa diganti dengan tiga dupa. (7) Tempatkan logo di bawah judul. (8) Perhatikan penulisan taling dan pepet. Tanda diakritik belum muncul. (9) Perbaiki penulisan kata ulang, pemengalan suku kata, (10) Beberapa gambar tidak mendukung sehingga dalam kamus cetak gambar tersebut dihapus. (11) Ada lema sama tetapi beda makna. (12) Pakaian yang digunakan dalam gambar seharusnya pakaian tari formal. (13) Ada makna yang kurang jelas.(14) Makna hendaknya kontekstual. (15) Harap konsisten dengan istilah (agem kenawan atau agem kanan). (16) Hindari penjelasan seperti tari pendet. (17) Terjemahan bahasa Inggris ada yang janggal, tidak gramatikal, dan ejaan salah. (18) Ada istilah yang tidak perlu diterjemahkan. (19) Gambar harus fokus. (20)

Dilihat dari sisi leksikografi, ada beberapa hal yang menjadi permasalahan dalam kamus, yaitu (1) penggunaan tanda titik (.) untuk pemenggalan lema dan sublema; (2) Penggunaan huruf kapital/kecil pada setiap lema dan sublema; (3) Penggunaan tanda hubung ganda/dash (--), tilde $(\sim)$, tanda anak panah $(\rightarrow$, dan singkatan. (4) penulisan lema dan sublema ; (5) pendefinisian lema dan sublema; (6) penggunaan tanda polisemi dan homonimi; (7) penggunaan imbuhan nasal; (8) penggunaan tanda diakritik untuk membedakan bunyi e dan é.

Rangkuman hasil FGD setelah dicermati dan dikaji oleh tim peneliti kemudian ditindaklanjuti dalam pertemuan khusus dengan agenda 
Revisi Kamus Seni tari Pasca FGD 5 dan 6 Juli 2019. Kegiatan revisi dilakukan pada tanggal 30 Agustus 2019 dengan kembali mengundang perwakilan lima kelomok ahli. Adapun tugas mereka sebagai berikut. Terkait bidang tari, tugas mereka adalah menambahkan dan merevisi istilah tari yang belum tercantum pada kamus terbitan perdana dari segi (1) ketepatan istilah tari yang ada dalam kamus; (2) ketepatan deskripsi makna masing-masing istilah tari dari segi isi/konten; (3) pemunculan istilah tari yang ganda; dan lain-lain yang relevan. Terkai dengan bidang kamus, tugas mereka adalah menyempurnakan/merevisi

kelengkapan dan ketepatan petunjuk kamus yang meliputi (1) ketepatan penyebutan, penempatan lema, dan sublema; (2) definisi/deskripsi makna berdasarkan teori leksikografi dengan berkoordinasi kapada ahli tari; dan lain-lain. Terkait dengan bidang bahasa Bali, tugas mereka adalah (1) memperbaiki ketepatan bentuk lema dan sublema/turunan istilah tari dengan berkoordinasi kepada ahli tari dan (2) memperbaiki penulisan istilah seni tari sesuai ejaan bahasa bali yang berlaku. Terkait dengan bidang bahasa Indonesia, tugas mereka adalah (1) memperbaiki definisi/deskripsi makna bahasa indonesia dari segi isi dengan berkoordinasi kepada ahli tari dan (2) memperbaiki deskripsi makna bahasa indonesia dari segi kaidah bahasa indonesia baku (lgika, gramatika, dan ejaan bahasa indonesia). Terkait dengan bidang bahasa Inggris, tugas mereka adalah (1) memperbaiki definisi/deskripsi makna bahasa inggris dari segi isi dengan berkoordinasi kepada ahli bahasa Indonesia dan ahli tari dan (2) memperbaiki deskripsi makna bahasa Inggris dari segi kaidah bahasa Inggris baku.

Terkait dengan bidang umum di luar bidang-bidang di atas menjadi kewajiban tim peneliti dengan tugas memperbaiki/menyempurnakan (1) kemenarikan sampul depan; (2) kemenarikan tampilan tulisan pada sampul depan (jenis huruf dan font); (3) kemenarikan tampilan tata letak tulisan sampul depan;

kemenarikan tampilan judul; (5) kemenarikan huruf yang dipakai; (6) kejelasan dan ketepatan judul; (7) kejelasan isi bagian prakata sehingga mudah dipahami; (8) sistematika sajian prakata ; (9) kejelasan isi bagian pendahuluan sehingga mudah dipahami; (10) sistematika sajian bagian pendahuluan dan lain-lain. Di samping itu, setelah menampung semua revisi masing-masing bidang, peneliti juga juga melakukan revisi terhadap hal-hal berikut. (1) Semua gambar pada kamus versi cetak dihilangkan atau dihapus karena gambar sudah ada pada kamus versi android. Di samping itu, gambar yang ada pada kamus versi cetak dalam beberapa hal justru mengaburkan makna istilah tari; (2) Setiap huruf pertama pada setiap lema/istilah diganti dengan huruf kecil; (3) Menghapus semua singkatan Ind. (Indonesia) di depan deskripsi makna bahasa Indonesia dan singkaan Ing. (Inggris) di depan deskripsi makna bahasa Inggris; (4) Mencetak miring setiap deskrispsi makna bahasa Inggris; (5) Semua istilah dianggap lema atau tidak ada 
lagi istilah lema dan sublema; (6) Menambah sejumlah lema/istilah yang belum tercantum pada kamus seni tari tahun I; (7) Menata ulang posisi lema secara alfabetis; (8) Menyempurnakan definisi lema sesuai deskripsi konseptual dan definisi logis terhadap sejumlah lema; (9) Istilah yang yg tidak tergolong seni tari (tari Sang Hyang) akan dikeluarkan dari Kamus Seni tari seperti tari gebug ende dan geret pandan; (10) Istilah tari yang berbeda antardaerah seperti aad ato eed dan ngaad ato ngeed) masing-masing dimunculkan pada kamus secara alfabetis; (11) Istilah yang berkaitan dengan busana tari tidak dilengkapi dengan gambar ; (12) Informan ketika direkam gerakannya tidak enggunakan pakaian formal sesuai dengan jenis tari yang dibawakan dengan tujuan untuk lebih memperjelas tampilan masingmasing gerak tari. Hasil revisi terhadap semua unsur revisi tersebut bisa dilihat langsung pada kams. Di samping itu, disepakati juga revisi petunjuk penggunaan kamus seperti yang tercantum pada bagian awal kamus.

Berkaitan

pengembangan kamus, diperoleh hasil sebagai berikut. Jumlah istilah tari yang berhasil dikembangkan sebanyak 947 buah. Dengan demikian jumlah istilah tari secara keseluruhan pada kamus hasil penelitian tahun II mencapai buah. Jumlah lema sebanyak itu terdiri atas lema yang dimlai dengan huruf $\mathrm{A}=76$ buah; huruf $B=105$ buah; huruf $C=16$; huruf $D=17$ buah; huruf $E=9$ buah; huruf $\mathrm{G}=39$ buah; huruf $\mathrm{I}=9$ buah; huruf $\mathrm{J}=20$ buah; huruf $\mathrm{K}=50$ buah; huruf $\mathrm{L}=33$ buah; huruf $\mathrm{M}=72$ buah; huruf $\mathrm{N}=231$ buah; huruf $\mathrm{O}=9$ buah; huruf $\mathrm{P}=61$ buah; huruf $\mathrm{R}=23$ buah; huruf $\mathrm{S}=82$ buah; huruf $\mathrm{T}=64$ buah; huruf $\mathrm{U}=11$ buah; dan huruf $\mathrm{W}=20$ buah. Penggunakan metode FGD ternyata efektif dalam rangka pengembangan jumlah lema maupun dalam menyerasikan deskripsi makna bahasa Indonesia dan bahasa Inggris. Di samping itu, dengan FGD, tercipta adanya penyamaan persepsi tentang bentuk lema yang benar; posisi lema secara alfabetis; ketepatan deskripsi makna bahasa Indonesia dan bahasa Inggris; kehadiran gambar pada kamus cetak; tampilan gambar pada cover; penggunan huruf pada cover; dan sebagainya. Selanjutnya, data yang berupa kelengkapan rekaman gambar/rekaman video berbagai gerak tari telah berhasil ditambahkan 152 gambar dari beberapa jenis tari. Hasil akhir terhadap semua kegiatan revsi di atas dapat dilihat pada Kamus Seni Tari Edisi II.

\section{Upaya Pelestarian Bahasa dan Budaya Bali Melalui Penyusunan Kamus Seni Tari Bali}

Penyusunan kamus seni tari Bali dapat dijadikan sebagai salah satu upaya peletarian bahasa dan budaya Bali karena beberapa logika berpikir berikut.

\section{Keunggulan Kamus}

Kamus seni tari Bali yang dikembangkan memiliki keunggulan tersediri yang berbeda dari kamus seni tari Bali yang beredar belakangan ini. Dibandingkan kamus seni tari lainnya, Kamus Seni Tari Bali ini memiliki beberapa kelebihan yaitu 
menggunakan media gambar, berbasis teknologi android, dan menggunakan tiga bahasa (Bali, Indonesia, dan Inggris). Dengan menggunakan media gambar, makna suatu istilah tari akan menjadi semakin jelas. Dengan dua keunggulan ini, seseorang akan lebih mudah memahami dan memperagakan setiap istilah gerakan tari Bali dan pada akhirnya lebih mudah dalam belajar tari Bali. Kedua keunggulan ini juga mampu memotivasi pembelajar tari di Bali khususnya untuk membaca kamus, belajar bahasa Bali, belajar tari Bali, dan secara tidak langsung dapat menumbuhkembangkan rasa cinta terhadap bahasa Bali. Rasa cinta terhadap bahasa Bali sebagai salah satu cerminan sikap positif terhadap bahasa Bali merupakan modal untuk melestarikan bahasa Bali sealigus budaya Bali. Hal ini bisa dipahami karena bahasa Bali merupakan salah satu unsur budaya Bali sekaligus pembentuk budaya Bali. Dengan menggunakan bahasa Indonesia dan bahasa Inggris, kamus ini akan bisa berlaku secara nasional, tetapi juga secara internasional. Di balik itu, ada juga beberapa masukan dari validator yang perlu ditindaklanjuti oleh tim peneliti dalam rangka penyempurnaan kamus ke depan.

\section{Kamus sebagai Penguatan Benteng Budaya}

Keberadaan kamus seni tari semacam itu tidak hanya dalam rangka memperluas wawasan terhadap berbagai ungkapan simbolik seni budaya Bali, tetapi juga dalam rangka penguatan benteng budaya, pelestarian budaya, dan strategi budaya Bali. Hal ini terkait dengan keberadaan seni sebagai fenomena budaya yang dapat menginspirasi bagi pengembangan seni budaya dan pembentuk kepribadian masyarakat Bali. Sebagai pembentuk kepribadian masyarakat Bali, keberadaan tari sebagai produk budaya yang fungsional di dalamnya terkandung nilai-nilai yang sangat kompleks. Kandungan nilai-nilai seperti nilai religius, etis, dan estetis manjadikan seni tari semakin berfungsi dalam kehidupan masyarakat pendukungnya. Berpijak dari keberadaan seni tari semacam itulah diperlukan adanya penyususnan kamus tari sebagai salah satu upaya strategis untuk menjaga kebertahannya.

Keberadaan kamus tari berbasis media gambar dan teknologi android yang dikembangkan merupakan arena konstruksi budaya dalam memepertahankan budaya lokal khususnya tari Bali, baik dalam konteks bentuk, fungsi, dan makna maupun dalam kaitannya dengan pewarisan nilai-nilai yang terkandung dalam seni tari. Pemertahanan budaya lokal, khususnya seni tari Bali dalam hal ini merupakan suatu langkah, cara untuk menjaga sesuatu supaya tetap utuh dan menjadi lebih baik. Mempertahankan suatu seni tari dapat dilakukan dengan cara mendalami atau paling tidak mengetahui seni tari itu sendiri, yang lebih lanjut dapat memahami dan menguatkan nilai-nilai budaya yang terkandung di dalamnya. Mempertahankan nilai-nilai seni budaya lokal dilakukan dengan mengembangkan perwujudannya yang bersifat dinamis, luwes dan 
selektif, serta menyesuaikan dengan situasi dan kondisi masyarakat yang selalu berubah dan berkembang ( Khutniah dan Ryanti, 2012). Dalam konteks seni tari Bali yang dikembangkan masyarakat Bali, dinamika nilai-nilai yang terkadung dalam seni tari Bali terbingkai dalam kearifan lokal Desa, Kala, Patra. Pemertahanan seni tari dengan nilainilai budaya yang terkandung di dalamnya tentu saja didasarkan pada kesadaran dinamik sosial budaya yang terklasifikasikan dan mengacu kepada kearifan lokal Rwa Bhineda baik dalam konteks keruangan ulu teben; segara gunung; masa lalu, masa depan; kebot kenawan;kaula lan gusti;rangda dan barong laki perempuan, baik dan buruk, keras dan lembut. Klasifikasi oposisi biner semacam itu dalam konteks budaya Bali semacam itu menjadi kekuatan bagi pengembangan kesadaran akan warna warni kehidupan yang memang harus diakui akan selalu ada sepanjang jaman dan menjadi alternatif pilihan dalam kehidupan masyarakat Bali yang harus dipertanggungjawabkan kepadaNya yang terkemas dalam gagasan hukum karma pala. Sehubungan dengan hal itulah masyarakat Bali yang beragama Hindu harus selalu menyadari akan kewajibannya untuk selalu melakoni kehidupan sebagai sebuah yadnya/ persembahan ke hadapan Tuhan Yang maha Kuasa. Hal inilah yang menjadi spirit dari setiap seniman dalam proses kreasi seni tarinya di Bali.

Kepunahan suatu bahasa dapat membawa dampak yang sangat fatal, terutama jika dilihat dari sudut pandang kehilangan budaya (Fishman, 1996). Bahasa dan budaya merupakan dua hal yang bertalian erat dan tak dapat dipisahkan (Reyhner, 1999). Menurut Fishman (1966), antara bahasa dan budaya memiliki beberapa jenis hubungan. Ada hubungan indeksikal antara keduanya. Di samping itu, seperti telah disampaikan di atas, keduanya memiliki hubungan simbolik, dalam arti seluruh kebudayaan itu dipertahankan oleh bahasa. Bahasalah yang merepresentasikan budaya itu dengan segala aspeknya, baik di dalam pikiran penutur bahasa itu maupun di dalam pikiran pihak luar. Namun, hubungan terpenting antara bahasa dan budaya, yang menyebabkan kehilangan terbesar ketika suatu bahasa punah, adalah sebagian besar budaya kita ada di dalam bahasa dan diekspresikan melalui bahasa. Karena demikian halnya, wajarlah kalau Dawson (dalam Anonby, 1999) mengatakan bahwa tanpa bahasa, budaya akan mati.

\section{Simpulan}

Berdasarkan pembahasan di atas, dapat ditarik dua buah simpulan, yaitu :

(1) pengembangan kamus seni tari Bali dapat dilakukan melalui penerapan model penelitian pengembangan yang diadaptasi dari pengembangan perangkat pembelajaran model 4-D, yang meliputi Define, Design, Develop, dan Disseminate.

(2) Penyusunan kamus seni tari Bali dapat dijadikan sebagai salah satu upaya peletarian bahasa dan budaya Bali karena (1) kamus ini memiliki beberapa 
kelebihan yaitu menggunakan media gambar; berbasis teknologi android; dan menggunakan tiga bahasa (Bali, Indonesia, dan Inggris). Dengan menggunakan media gambar, makna suatu istilah tari akan menjadi semakin jelas. Dengan dua keunggulan ini, seseorang akan lebih mudah belajar tari Bali. Kedua keunggulan ini juga mampu memotivasi pembelajar tari di Bali, khususnya, untuk membaca kamus seni tari dan belajar tari Bali; dan secara tidak langsung dapat menumbuhkembangkan rasa cinta terhadap bahasa Bali. Rasa cinta terhadap bahasa Bali sebagai salah satu cerminan sikap positif terhadap bahasa Bali merupakan modal utama untuk melestarikan bahasa Bali sekaligus budaya Bali. Hal ini bisa dipahami karena bahasa Bali merupakan salah satu unsur budaya Bali sekaligus pembentuk budaya Bali. Keberadaan kamus seni tari semacam itu tidak hanya dalam rangka memperluas wawasan terhadap berbagai ungkapan simbolik seni budaya Bali, tetapi juga dalam rangka penguatan benteng budaya, pelestarian budaya, dan strategi budaya Bali. Hal ini terkait dengan keberadaan seni sebagai fenomena budaya yang dapat menginspirasi bagi pengembangan seni budaya dan pembentuk kepribadian masyarakat Bali.

\section{Saran}

Dalam upaya pelestarian bahasa dan budaya Bali, perlu dikembangkan berbagai kamus istilah yang berkaitan dengan budaya Bali yang berbasis media gambar dan teknologi android dengan menggunakan mdel pengembangn kamus di atas.

\section{Daftar Pustaka}

Alavi M.M.A, Abhayaratne G.T.A, Zafran M.R.M, Rangari H.A.T and Dhishan Dhammearatchi, 2016. Smartkid: An AndroidBased Language Development Application For Preschoolers, A Multidisciplinary Journal of Scientific Research \& Education, 2(11), November2016, Volume: 2, Issue: 11

Anonby, Stan J. 1999. "Reversing Language Shift: Can Kwak'wala Be Revided". Dalam Reyhner, John et.al. (eds.). Revitalizing Indigenous Languagesi. Flagstaff, AZ: Northern Arizonazona University.

Badudu, J.S. 2003. Kamus Kata-kata Serapan Asing dalam Bahasa Indonesia. Jakarta: PT Kompas Media Nusantara

Bandem, I Made, dkk. 1983. Gerak Tari Bali (Laporan Penelitian) 1983. Ensiklopedi Tari Bali. Denpasar: Perc. PT Bali Post Offset 1996. Evaluasi Tari Bali. Yogyakarta: Percetakan Kanisius

Brataatmaja, T.H.K., dkk. 1985. Khazanah Lawan Kata (Antonim). Jakarta: Departemen Pendidikan dan Kebudayaan. 
Departemen Pendidikan dan Kebudayaan. 1993. Panduan Penyusunan Kamus Bidang Ilmu. Jakarta: Depdikbud.

Departemen Pendidikan Nasional. 2008. Kamus Besar Bahasa Indonesia. Edisi Keempat. Jakarta: PT Gramedia Pustaka Utama.

Djendra, I Nyoman. 2012. Kamus Ideal Bahasa Bali, BaliIndonesia. Denpasar: Yayasan Dharma Pura

Eco, Umberto. 2004. Tamasya Dalam Hiperrealitas. Jalasutra: Yogyakarta. 2009. Teori Semiotika. Bantul:

Kreasi Wacana.

Fishman, Johsua. 1996. "What Do You Lose When You Lose Your Language". dalam Cantoni, G. (ed.). Stabilizing Indigenouse Languages. Flagstaff: Center for Excellence in Education, Northern Arizona University. Franza, Ni Putu Sinria; Sudana, A A K Oka; Wibawa, Kadek Suar. 2016. Application of Basic Balinese Dance Using Augmented Reality on Android, Journal of Theoretical and Applied Information Technology; Islamabad90 (Aug 2016): 61-66. Gunta Chomchalerm, Jitsupha Rattanakajornsak, Unchalee Samsrisook Damras W ongsawang, W orapan Kusakunniran. 2014. Braille Diet: Dictionary Application for the Blind on Android Smartphone, 2014 Third ICT International Student Project Conference (ICT-ISPC2014)

Hoed, Benny H. 2004. Bahasa dan Sastra dalam Tinjauan
Semiotika dan Hermeneutik, dalam Semiotika Budaya. Depok: Universitas Indonesia. Hoed, Benny H. 2011. Semiotika dan Dinamika Sosial Budaya. Depok: Komunitas Bambu.

Hugeng Hugeng and Edbert Hansel, 2015. Implementation of Android Based Speech Recognition for Indonesian Geography Dictionary, ULTIMA Computing, Vol. VII, No. 2, 2015

Hwang, S.M., Lee, J., 2014, "A Development of Translation Dictionary KRdict on Android", Journal of Security Engineering;Feb2014, Vol. 11 Issue 1, pp. 101

Jones, M.D., Hamilton, H., James, P., 2015, "Mobile Phone Access to a Sign Language Dictionary", Proceedings of the 17th International ACM SIGACCESS Conference on Computers \& Accessibility, pp. 331-332

Kantor Dokumentasi Budaya Bali Provinsi Bali. 2000. Pendokumentasian Gerak-Gerak Tari Bali. Denpasar: Kantor Dokumentasi Budaya Bali Provinsi Bali

Kersten SVD, J. 1984. Bahasa Bali (Tata Bahasa dan Kamus Bahasa Lumrah). Ende Flores : Nusa Indah,

Ketty Chachila, Adeline Engkamatb, Adib Sarkawic, Awang Rozaimi Awang Shuibd. 2015. Interactive Multimedia-based Mobile Application for Learning Iban Language (I-MMAPS for Learning Iban Language), Procedia - Social and 
Behavioral Sciences 167 ( 2015 ) $267-273$

Kridalaksana, H. 1981. Kamus Sinonim Bahasa Indonesia. EndeFlores: Nusa Indah.

Kridalaksana, H. 1993. Kamus Linguistik. Jakarta: Gramedia.

Li, C. M., 2014, "Design and Development of English Electronic Dictionary Based on Android Platform", Advanced Materials Research, Vols. 912-914, pp. 1197-1200,

Liu, X. Y., Shen, J., 2014, "Design and Implementation of English Electronic Dictionary System for Android", Applied Mechanics and Materials, Vols. 631-632, pp. 1003-1006

Miss. Priyanka V. Mhamunkar, Mr. Krishna S. Bansode and Prof. Laxman S. Naik. 2013. Android Application to get Word Meaning through Voice, International Journal of Advanced Research in Computer Engineering \& Technology (IJARCET) Volume 2, Issue 2, February 2013

Muhammad Nasir Ibrahim, Siti Noormaya Bilmas, Mariani Idroas, 2014. Arabic Dictionary Application for Android Devices, Australian Journal of Basic and Applied Sciences, 8(24) Special 2014, Pages: 184-190

Pilliang, Yasraf. 2003. Hiper Semiotika. Tafsir Cultural Studies Atas Matinya Makna. Yogyakarta: Jalasutra.

Reyhner, Jon. 999. "Some Basics of Indigenous Language Revitalization". dalam Reyhner, John et.al. (eds.) Revitalizing Indigenous
Languages. Flagstaff, AZ:

Northern Arizona University. Rusmana, Dadan. 2014. Filsafat Semiotika. Bandung: Pustaka Setia.

Simpen AB, I W. 1983. Kamus Bahasa Bali. Denpasar: PT Mabhakti

Sobur, Alex. 2006. Semiotika Komunikasi. Bandung: Remaja Rosdakarya.

Suandi, I Nengah, dkk. 2015. Kamus Serapan dalam Bahasa Bali. Yogyakarta: Larasan

Suhailah Mohd Yusof, Siti Nur Shuhada Shalan, Syahirah Almuddin, Phaveena Primsuwan, Norlizawati Md Tahir, Rosmaiza Abd Ghani, 2015. A-Grammar: Mobile Learning Foundation of Arabic Grammar Language with Multimedia Aided Approach, 2015 International Symposium on Mathematical Sciences and Computing Research (iSMSC)

Sukayana, I Nengah. 2013. Kamus Budaya Bali I. Denpasar: Balai Bahasa Provinsi Bali

Sun Myung Hwang and Jihyun Lee, 2014. A Development of Translation Dictionary KRdict on Android, Journal of Security Engineering Vol.11, No.1 (2014), pp.101-114

Svensen, Bo. 1993. Pratical Lexicography; Principles and Methods of Dictionary-Making. New York: Oxford University Press

Thiagarajan, S., Semmel, D.S.\&Semmel, M.L. 1974. Instructional Development for Training Teacher of Exceptional Children. Minnesota: Indiana University 
Zgusta, L. 1971. Manual of Lexicography. Mouton: The Hague. 